\title{
Self Determination Theory to Explain Charismatic Leadership in Virtual Teams: Proposing an Integrated Model
}

\author{
U.L.T.P. Gunasekare ${ }^{1}$ \\ ${ }^{1}$ Faculty of Commerce and Management Studies, University of Kelaniya, Sri Lanka \\ Correspondence: U.L.T.P. Gunasekare, Senior Lecturer Grade 1, Faculty of Commerce and Management Studies, \\ University of Kelaniya, Sri Lanka. E-mail: thamarag@kln.ac.lk
}

Received: April 5, 2016

doi:10.5430/ijba.v7n3p132
Accepted: May 2, 2016

Online Published: May 9, 2016

URL: http://dx.doi.org/10.5430/ijba.v7n3p132

\begin{abstract}
The goal of this paper is to review the concept of Charismatic Leadership in virtual teams within the self- determination framework and develop a model to explain how charismatic leadership caused self-determined behaviors. Since virtual context is reasonable for self-determined behavior, it is assumed that, charismatic leadership in virtual teams promotes autonomous motivation in followers and finally leads self-determined behavior by way of satisfying follower need for autonomy, need for competence and need for relatedness. The objective of this paper is to widening the understanding of charismatic leadership in a different context (i.e. in virtual teams) with the supplement of best validated theory of motivation. The implication of this paper provides theoretical explanation of effects of charismatic leadership from the perspective of Self Determination Theory (SDT) which will be a novel interpretation to both these theories. Additionally this investigation raises understanding of motivational effects of charismatic leadership in the virtual context.
\end{abstract}

Keywords: charismatic leadership, self determination theory, need for autonomy, need for competence, need for relatedness

\section{Introduction}

It is accepted that leadership is one of the key factors for organizational success (Yukl, 2010) and it is at the topmost research agenda in the arena of management. Charismatic Leadership theory has been the concentration of many leadership research studies (Yukl, 1999), and this approach has helped to shift the leadership paradigm to where it is today (Antonakis, Cianciolo, \& Sternberg, 2004; Conger, 1999; Hunt, 1999; Lowe \& Gardner, 2000). Also charismatic leadership notion as a research stream, dominates the leadership landscape, whether deservingly or not, at least in terms of published papers in the premier academic journals, focused on leadership, both in the last decade (Lowe \& Gardner, 2000) and in this decade as well.(W.L.Gardner, Lowe, Moss, Mahoney, \& Cogliser, 2010).

In this new genre of theory, charisma is a prime concept in all of them, either explicitly or implicitly. As, all these studies revealed, charismatic leadership causes followers to become highly committed to the leader's mission, to make significant personal detriments in the interest of the mission, and to perform above and beyond the call of duty. Theories of charismatic leadership further point out such effects as emotional affection to the leader on the part of the followers; emotional and motivational arousal of the followers; enhancement of follower valences with respect to the missions articulated by the leader; follower self-esteem, trust, and confidence in the leader; follower values; and follower intrinsic motivation (Shamir, House \& Arthur, 1993).

However, all these researchers seem to have overlooked one aspect of central ideology of this theory: That is how it focused on fulfillment of followers' psychological needs and then it is capable to generate follower autonomous motivation through the fulfilment of their intrinsic motives. Follower autonomous motivation is certainly significant in the virtual setting, since physical non presence of the leaders is exemplified in virtual context and followers' autonomous motivation for self-determined behavior remarkably causes fulfilment of leaders' expectations in virtual context. In virtual teams the leader's role is critical in creating followers' consistency and cohesion as well as their self-motivation to contribute to the given task. Nevertheless, due to the lack of physical proximity, the virtual world requires leaders to be proactive and interactive with followers to perform their own and to adjust the effort and strategies for building intense motivation and further relationships for fulfilment of the task. 
According to the Charismatic leadership theory charismatic leaders use their vision and mission as a platform to implicate the self-concept of followers. In this way, leaders have extraordinary effects on followers, whom are inspired by increased levels of self-esteem, self-worth, self-efficacy, collective efficacy, identification with the leader, social identification, and value internalization. Shamir et al. (1993) stated that these outstanding leaders affect followers, as a result of motivational mechanisms that are persuaded by the leaders' behaviors. (House and Shamir, 1993)

Within this background, it appears surprising that this central ideology of charismatic leadership theory with respect to follower autonomous motivation to the leaders' expectations, specifically in virtual setting is significant for further studies and has not yet significantly explored. This study attempts to address this research gap, by explaining the associations between charismatic leadership in virtual teams and team member' intrinsic need fulfillment (within the self-determination theory (SDT) framework), as a theoretical explanation, to envisage this leadership theory, from the followers' self-determination aspect and finally, to propose an integrated model to describe charismatic leadership in virtual teams. To explore followers' needs, the self-determination theory (SDT) (Deci \& Ryan, 2000; Gagné \& Deci, 2005), which is considered as one of the most comprehensive and best validated frameworks of psychological needs is employed. SDT postulates the presence of three universal needs: the needs for autonomy, for competence, and for relatedness. According to SDT, the contentment of these needs is necessary for optimum follower performance. (Deci, Connell, \& Ryan, 1989)

In this study, by integrating charismatic leadership theory and SDT within the virtual context, it is assumed that the basic need fulfilment facilitates the link between charismatic leadership and follower outcomes. More specifically, it is proposed that via charismatic relationship, as Conger and Kanungo (1998) explicated (formulation and articulation of a strategic vision, sensitivity to the environment, sensitivity to member needs, personal risk, and unconventional behavior), virtual leaders fulfil the intrinsic needs of their followers. And the satisfaction of these intrinsic needs (needs for autonomy, needs for competence and needs for relatedness), generate autonomous motivation towards follower performance which is greatly essential in virtual context. Furthermore, via motivated by way of these need satisfaction, autonomous motivation is generated to display self-determination behavior in followers, that directs the followers to work with less supervision and guidance from the part of the leader in the virtual context. Certainly the link between charismatic leadership and followers' automatous motivation is mediated by the assumptions in Self Determination Theory. By integrating this prominent theoretical approach of motivation with charismatic leadership, present study tried to explore the charismatic leadership process and, explain the follower automatous motivation in virtual context.

The present study strives for making four important contributions to the leadership literature. First, by investigating the contentment of basic psychological needs as a mechanism of leadership stimulus, it analyzes how charismatic characteristics fulfill followers' three basic psychological needs (need for autonomy, need for competence, and need for relatedness). Second, this examines, in consequence of fulfilment of these basic needs, how charismatic leadership behaviors, stimulate follower autonomous motivation in virtual team. In working on this, it is assumed that this inquiry may deliver valuable insights into how this leadership style can be linked to different positive follower outcomes. Third, this analysis may illustrate the charismatic effects to SDT, which, in its current form, does not make such link with any motivational predictions (Sheldon \&Filak, 2008). Fourth, the theoretical explanation of the proposed model integrates the charismatic leadership perspective and Self Determination Theory which will be a novel interpretation to both these theories. Additionally this investigation supplement the understanding of motivational effects of charismatic leadership in the virtual context. As for the practice of leadership, practical implications can be explained on how SDT can be helpful in constructing a motivational workplace for virtual teams.

\section{Self-Determination Theory (SDT)}

SDT is a motivation theory, based on the idea that people willingly seek prospects to develop their fullest potentials. As they seek such opportunities, it enhances their psychological wellbeing which develops their inner striving conditions towards optimal performance. (Deci\& Ryan, 2000) Recent critics stated that SDT is "an impressive accomplishment" (Psyszczynski, Greenberg \& Solomon, 2000), provides "new impetus to research on human motivation" (Coleman, 2000), and may be "the most ambitious contribution to what some have termed as the rebirth of motivational research" (Hennessey, 2000). However, organizational studies scholars have been relatively slow to apply this theory, perhaps because of a lack of understanding of SDT's current formulation. (Ambrose and Kulik (1999)

The starting point of the self-determination theory (SDT; Deci\& Ryan, 2000) is the assumption that motivation towards growth, development and integrity is inherently rooted in humans. Accordingly, growth and development of humans do not happen automatically as their innate nature. Therefore, SDT postulates that fundamental nutrimentsnamely, satisfaction of innate basic psychological needs - are required for ongoing growth and development of humans. Only when these needs are satisfied psychological well-being and optimal functioning can occur in humans. 
According to Deci and Ryan (2000), there are three basic psychological needs that refer to life-long innate tendencies toward achieving coherence, effectiveness, and connectedness: need for autonomy, need for competence, and need for relatedness/affiliation. Need for autonomy refers to, need to self-organize one's behavior by involving a sense of choice and desire and a feeling of not being controlled by any other forces alien to the self (Deci\& Ryan, 2000). Need for competence concerns feelings of being capable of mastering new skills and the environment and feelings of being effective, i.e., being able to achieve desired outcomes. Need for relatedness/affiliation refers to the senses of connectedness and association involving a feeling of being significant to the others and belonging within one's community. According to the theory, motivation is determined by the extent to which these needs are satisfied.

In reviewing the studies that have specified the social contextual conditions that create intrinsic motivation and facilitate internalization and integration of extrinsically motivated tasks, it was found that social-contextual actions like positive and promoting feedback, progressive communication (Vallerand\& Reid ,1984), and supportive evaluations and rewards (Deci, 1975), induce feelings of competence that can enhance intrinsic motivation. More clearly that says, social contextual conditions that support one's feelings of competence, autonomy, and relatedness are the basis for preserving intrinsic motivation and becoming more self-determined and autonomous. It was pointed out that in situations, where more self-determined behaviors are required, more the conditions that allow satisfaction of these three basic human needs which support the innate needs to feel connected, competences and autonomy. In the development of this proposed model, it is assumed that charismatic leadership provides this contextual condition which supports the individuals to be intrinsically motivated.

\section{Conger-Kanungo Model of Charismatic Leadership}

Conger and Kanungo conceptualized the relationship between leader behavior and the effective performance of an organization, according to the qualities attributed to leaders by their followers (Conger and Kanungo 1998). Based on the ideas of Max Weber on charisma and charismatic authority, Conger and Kanungo (1998) suggested a refined version of charismatic leadership, proposing that charismatic leader is a paradigmatic form of the transformational leader. The attribution theory of charisma outlined certain behaviors and processes that, when adopted by the leader, make him seems charismatic in the eyes of followers and then they become more influential. Such attributes include the leader's challenging the current status quo, employing unconventional means in realizing vision, taking personal risks, projecting confidence, being persuasive and motivating others. This paper attempts to map the psychological aspect of followers via SDT, with charismatic leadership behaviors. The model developed by Conger and Kanungo is justified to apply in this proposed model, since it refers how charismatic behaviors influence self-concept of followers and it brings more consistency to the study's purpose.

Conger and Kanungo (1987) explained charismatic leadership as an attributional phenomenon and proposed a framework for examining the behaviors of charismatic leaders. They further explained that the assemblage of these leadership behaviors lead to followers' attributing them with having charisma. These charismatic behaviors include presenting an idealized vision dissenting from the status quo, taking personal risks, engaging in self-sacrifice to accomplish the envisaged vision, using exceptional and unconventional strategies, credibly assessing the environment, pronouncing motivation to lead, engaging in exemplary behavior, and performing as agents of fundamental changes. As a segment of their research on charismatic leadership, Conger and Kanungo, (1987) proposed a complementary theory, as a theoretical model for charismatic leadership theories. Conger and Kanungo (1998) conveyed that, the three studies conducted in the United States, Canada and India confirmed their findings further. The outcomes of these three separate studies revealed acceptable reliability and validity of this model as an analytical tool in multicultural contexts. Conger and Kanungo's (1998) research generated a model, which composed of three stages that distinguished charismatic leadership from other leadership models. Their study favored the idea that charismatic leaders are skilled at encouraging followers to achieve superior goals, advanced performance and better satisfaction. This model for charismatic leadership addressed characteristics of leadership behavior that they believed were not addressed in pre-existing leadership literature. The key features describe the leaders' responsibility in three main stages:

Stage One - Critical assessment of the environment and status quo. During this stage leader is sensitive to the environment to identify the possibilities and opportunities in the environment and sensitive to the follower needs to ensure their followers needs can be investigated;

Stage Two - Formulation and articulation of a future vision or the formulation of goals for the follower; and

Stage Three - Building of trust and credibility in the minds of followers, which is crucial to developing commitment to a vision. In particular, leaders engage in personal risk, partly to inspire followers during role modelling, as well as to exhibit unconventional behavior. (Conger and Kanungo, 1998) 
Based on the above described two theories (Self-Determination Theory of motivation and Charismatic Leadership Theory of Conger and Kanungo), this paper propose a theoretical model to investigate the charismatic leadership in virtual teams.

\section{The Proposed Model}

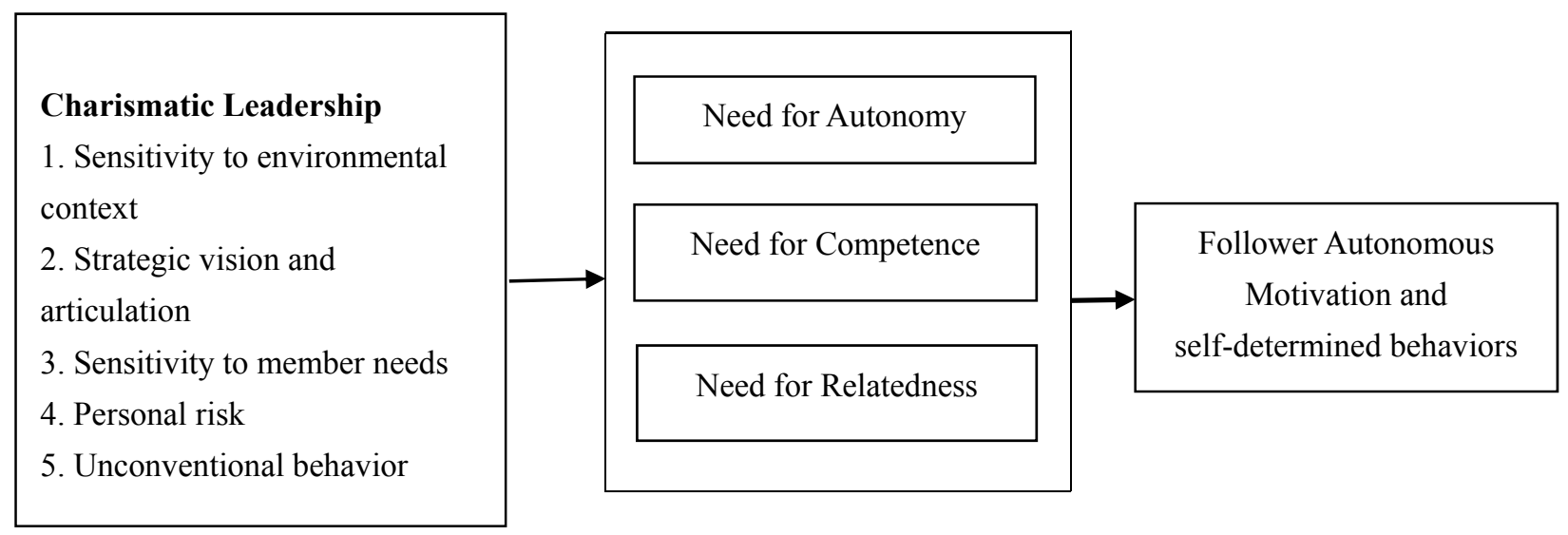

The model illustrates the five factors of charismatic leadership as outlined by Conger and Kanungo. These five factors of charismatic leadership are assessed according to the Conger and Kanungo Scales (CKS) of charismatic leadership. The argument in this study is these qualities of charismatic leadership fulfills the human needs explicated in SDT and provide the conditions for self-determined behaviors. The assumptions about need satisfaction and its motivational implications of SDT cause to propose a link between charismatic leadership and follower autonomous motivation towards exceptional performance in virtual teams. This model has two main parts: (a) charismatic leadership (b) need satisfaction and follower effects for autonomous motivation. This model link charismatic leadership theory with SDT and explicate virtual team as a conducive environment for charismatic leadership. In this way this study provides a stepping stone for leadership theory to broaden knowledge on leadership and for practice to gain insights to the pitfalls and strengthen the motivational leaders. In order to do justice to the complexity and explorative character of the study, the previous literature on charismatic leadership supported profoundly.

\section{Charismatic Leadership Behaviors towards Autonomous Motivation and Self-determined Behaviors}

The model proposed that charismatic leadership helps followers for their need satisfaction in terms of need for autonomy, need for competence and need for relatedness which finally leads to self-determined behavior in them. There are several ways that charismatic leaders help their followers to satisfy these three types of needs. The model suggests that the charismatic characteristics proposed by Conger and Kanungo support in this background. Charismatic leadership has been conceptualized as comprising five dimensions (Conger and Kanungo, 1998) sensitivity to the environment (i.e., leaders evaluate the status quo of the environment, they look for opportunities, resources and constraints including followers needs to improve the organizational processes actively), strategic vision (this strategic vision is articulated as an idealized goal which characterized as a highly desirable but difficult to achieve and this vision is communicated in an inspiring way), sensitivity to member needs (followers needs are evaluated and identified paying attention on followers individual needs, strengths, and aspirations in developing their capabilities), personal risk (engaging in charismatic role modeling that receives the belief and admiration of followers) and unconventional behavior (demonstrating the important means to achieve the vision and encouraging the followers to challenge the existing systems and find the ways to achieve the vision).

\subsection{Charismatic Leadership and Follower Need for Autonomy}

Empowerment literature identifies the empowering effect of an idealized vision. For example, Burke (1986) suggested that leaders empower their followers by providing clear direction, 'but not just a direction - a direction that comprises a higher purpose, a worthwhile cause, and meaningful idea. Agreeing with Bennis and Nanus (1985), the sense of creating a difference for the organization is a crucial component of empowerment. According to Kanungo and Mendonca (1996), leaders visualize and articulate an idealized future goal which provides energies and hence empower subordinates to the extent that these goals are internalized with them. Conger and Kanungo, held that, other 
than articulating and championing an energizing goal, charismatic leaders empower their followers by providing them sense of their personal efficacy. The charismatic leader conveys such information in different ways. These include: (1) voicing confidence in subordinates accompanied by high performance expectations (Burke, 1986; Conger, 1989; Conger and Kanungo, 1988; Shamir et al., 1993); (2) Provision of autonomy from bureaucratic constraints (Conger and Kanungo, 1988) and (3) Setting inspirational and highly meaningful goals (Bass, 1985; Conger and Kanungo, 1988; Bennis and Nanus, 1985; Burke, 1986).

Additionally, charismatic leaders inspire their followers to improve new methodologies to proficiently accomplish their work. Hence, they offer employees freedom and autonomy to execute and fulfill their tasks. As Kirkman et al. (2009) argued, employee involvement seems an important aspect of charismatic leadership behavior. As charismatic leaders make every effort to address followers' needs, for the attainment of group's goals as Shamir et al. (1993) suggested, they more likely to autonomously pursue these goals. Conger and Kanungo (1988) proposed that such heightened feelings of self- efficacy are serious to the psychological experience of empowerment. The empowerment research referred to above also recognizes a sense of competence as being essential to feelings of empowerment (Bennis and Nanus, 1985; Menon and Borg, 1995; Spreitzer, 1995; Thomas and Velthouse, 1990). According to Arnold et al. (2007) followers of charismatic leaders understand their work as more meaningful compared with the followers of non-charismatic leaders. In referring SDT, these leadership behaviors directly address followers' need for autonomy. The need for autonomy is nurtured by a leadership style that provides opportunities for involvement, providing meanings, identifies followers' perspectives, and inspires self-initiation (Deci et al., 1989). In summary, based on all the above findings, it is expected that charismatic leadership is certainly associated with followers' feeling of autonomy.

\subsection{Charismatic Leadership and Follower Need for Competence}

In charismatic leadership theory, followers' anticipations of effective performance and ongoing feelings of task achievement play a crucial role in successful outcomes. Returning to the notion that the goals and visions of charismatic leaders are most often patronizing and challenging, it would be expected that followers to recognize themselves as competent enough and have capacities to successfully undertake and accomplish a high level of task efforts (effort-accomplishment expectancies) (Conger and Kanungo, 1988; Shamir et al., 1993). Then they would experience the task demands of the charismatic leader with a sense of confidence which could lead to effective attempts. The leaders' quality of personal risk and unconventional behavior again, build self-efficacy to perform the given effort successfully (Conger and Kanungo, 1988). When charismatic leaders demonstrated the personal risk, it heightened the sense of task efficacy of followers which allows charismatic leaders to mobilize their vision. It allows leaders to set higher performance goals and to have them accepted. Finally, it helps in motivating subordinates to persist in efforts with sharpening their competencies. Especially, leaders personal risk taking results self-confidence, high task involvement, and to show commitment to the mission in followers. As conger and Kanungo, 1998, explained unconventional behavior demonstrate high impact in followers' self-efficacy which leads to sharpen the capabilities of followers. It leads to encourage new learning and setting a personal example in mind of the followers. By demonstrating determination, optimism, and self-confidence, a leader influence followers' sense of development and advancement towards the mission accomplishment (House \& Shamir, 1993). Furthermore, by setting him as a personal example, increases followers' higher aspiration for their growth and pursue growth potentials. (Yukl, 1999) As Conger and Kanungo (1998) noted, charismatic leaders formulate a set of idealized, future goals that represent the embodiment of a perspective shared by followers and that appear to satisfy their growth needs. Similarly, Conger and Kanungo (1998) found that leader charisma was positively related to follower task efficacy $(r=0.35, p<0.001)$ and feelings of empowerment $(r=0.31, p<0.001)$. Given that these previous research, it has been shown that charismatic leadership is associated with satisfaction of follower need for competence and having linked charismatic leadership to self-determination behavior.

\subsection{Charismatic Leadership and Follower Need for Relatedness}

One major characteristic of charismatic leaders is the sense of relatedness they foster among their followers. They do so by two ways: (i) by strengthening the magnetism between leader and followers and (ii) by growing the bond among followers (Kark et al., 2003). First, charismatic leaders by way of sensitivity to the environment and sensitivity to the follower needs, they engage in self-sacrificing activities and are willing to neglect their own comforts for the good of the group (Avolio, 1999). These leaders receive the veneration and admiration of their followers (Conger \&Kanungo, 1998). In line with this interpretation, Wang, Law, Hackett, Wang, and Chen (2005) described that charismatic leadership was positively linked to dyadic relationship between leaders and their subordinates. This, in other way, contributes in satisfying the need for relatedness. Further, charismatic leaders are predominantly apposite to stimulate 
their followers towards the mission and goals of the group (inspirational motivation). They do so by accentuating the prominence of the group's goals, evoking a feeling of relatedness among their followers. House (1977) proposed that the basis for the charismatic appeal is the emotional attachment that befalls between followers and their leader. Depending on the mission requirements, charismatic leaders arouse followers' motives to accomplish the leader's archetypes and values also. Followers in turn display affection, attachment and admiration for the leader, in whom their sentimentalities and ideals are expressed. SDT stresses that acknowledgement and support from other people who show genuine interest in one's thoughts and interests are important satisfiers of this need (Ryan \&Deci, 2008). As outlined earlier, charismatic leaders meet these conditions by fostering the bond between leader and follower and among each and every followers. Theoretically, these leaders focus followers on the mission of the group by arousing their need for achievement, affiliation, or power motives (Shamir et al 1993). Charismatic leaders communicate symbolically, use imagery, and are persuasive in communicating a vision that promises a better future for their followers. In this way, they create an intense emotional attachment with their followers.

SDT posits that fulfilment of need for relatedness is critically dependent upon the sense of connectedness to others (Deci\& Ryan, 2000). Charismatic leaders aim to enhance the salience of collective identities in the self-concepts of followers primarily to increase the probability that followers will engage in self- sacrificial and accommodating behaviors that advance the overall mission of the group rather than their own personal aims (Shamir et. al.1993).

According to the proposed model these characteristics of charismatic leaders give the followers opportunities to satisfy their psychological need and via this state of fulfilment, the followers transform their extrinsic motivation into intrinsic motivation and demonstrate self-determined behavior. Therefore it is theoretically justified that the characterization of charismatic leadership by Conger and Kanungo (sensitivity to the environment, sensitivity to the follower needs, strategic vision, personal risk and unconventional behavior) aids in realizing the followers need for autonomy, need for competence and need for relatedness. Accordingly in the language of SDT, because followers desire to achieve these needs to move their extrinsic motivation towards intrinsic motivation and finally behave in a self-determined way. Charismatic leadership behaviors promote these higher order needs satisfaction and induce the followers' autonomous behaviors. This is really, a significant condition for virtual teams as it operates in the no physical presences of the leadership.

\section{Conclusion and Implication for Future Research}

The proposed model presented in this paper explains that the charismatic leadership behaviors stimulate the follower self- determined behavior which is appropriate for virtual teams. The proposition established from this model is implicitly brings a strong foundation to elucidate this dynamic leadership behavior in the contemporary and innovative organizational designs such as virtual teams. Physical non presence nature of leadership is integral and autonomous motivation is compulsory in virtual setting,

This study represents a potentially important way that organizational research can help expand and improve upon SDT to another innovative direction. To formalize and summarize, this study offers the following proposition, which will generate new research avenues to the leadership research and mostly to the charismatic leadership research: Charismatic leaders fulfill follower autonomy needs, competence needs and relatedness needs and achieve intrinsic motivation which leads employee self-determine behavior. The future researchers may empirically validate this proposition and need to supplement the current theories. It is further presumed that this proposed model will contribute to the literature by adding valuable evidence to address the gaps in those issues relevant to charismatic leadership behaviors in virtual teams and issues relating to SDT. Additionally by concentrating in-depth on the information uncovered by this study and in understanding the employee behavior within the charismatic leadership framework further understanding could be accumulated to the body of knowledge. This is an important addition to the literature, and contributes to the field of organizational psychology by adding more evidence to advocate that leadership is associated with employee self-motivation. This study fills the gap left by earlier researchers since this reveals the charismatic characteristics has possible influencing ability to generate employee a self- motivation with the fulfilment of human needs. It is probable that future scholarships could usefully examine the interactivity between charismatic leadership and self-motivation with the moderating effect of other relevant contextual constructs. Most importantly, this research integrates leadership behavior and human motivation to stimulate the key relationships with virtual teams which leads to leader effectiveness. Finally, all the research constructs used in this model were drawn from literature, and were designed for future validation under any context including virtual context. 


\section{References}

Ambrose, M. L., \&Kulik, C. T. (1999). Old friends, New faces: Motivation Research in the 1990s. Journal of Management, 25, 231-292.

Antonakis, J., Cianciolo, A. T., \& Sternberg, R. J. (2004). Leadership: Past, Present, Future. In J. Antonakis, A. T. Cianciolo, \& R. J. Sternberg (Eds.), The nature of leadership (pp. 3-15). Thousand Oaks, CA: Sage.

Arnold, K. A., Turner, N., Barling, J., Kelloway, E. K., \& McKee, M. C. (2007). Transformational Leadership and Psychological Well-Being: The mediating role of meaningful work. Journal of Occupational Health Psychology, 12, 193-203.

Avolio, B. J. (1999). Full Leadership Development. Thousand Oaks, CA: Sage. In Timothy A. J. \& Ronald F. P (2004).Transformational and Transactional Leadership: A Meta-Analytic Test of Their Relative Validity. Journal of Applied Psychology, 89(5), 755-768.

Bennis, W., \& Nanus, B. (1985). Leaders: The Strategies of Taking Charge. Harper \& Row: New York.

Burke, W. W. (1986). Leadership as Empowering Others. InSrivastva, S. (Ed.), Executive Power (pp. 51-77). Jossey-Bass: San Francisco.

Coleman, P. G. (2000). Aging and the Satisfaction of Psychological Needs. Psychological Inquiry, 11, 291-293.

Conger, J. A. (1999). Charismatic and Transformational Leadership in Organizations: An Insider's Perspective on these Developing Streams of Research. The Leadership Quarterly, 10, 145-179.

Conger, J.A., \& Kanungo, R. N. (1988). The Empowerment Process: Integrating Theory and Practice. Academy of Management Review, 13(3), 471- 482.

Conger, J. A., \& Kanungo, R. N. (1987). Toward a Behavioral Theory of Charismatic Leadership in Organizational Settings. Academy of Management Review, 12, 637-647.

Conger, J. A., \&Kanungo, R. N. (1998). Charismatic Leadership in Organizations. Sage Publishers: Thousand Oaks, CA.

Conger, J. A. (1989).The Charismatic Leader. Jossey-Bass: San Francisco.

Deci, E. L. (1975). Intrinsic Motivation. New York: Plenum. In Ryan, R. M., Deci, E. L. (2000) Self-Determination Theory and the Facilitation of Intrinsic Motivation, Social Development, and Well-Being. American Psychologist, 55(1), 68-78.

Deci, E. L., Connell, J. P., \& Ryan, R. M. (1989). Self-Determination in Work Organization. Journal of Applied Psychology, 74, 580-590.

Deci, E.L., \& Ryan, R. M. (2000). Self-Determination Theory and the Facilitation of Intrinsic Motivation, Social Development, and Well-Being. American Psychologist, 55(1), 68-78.

Gagné, M., \& Deci, E. L. (2005). Self-Determination Theory and Work Motivation. Journal of Organizational Behavior, 26(4), 331-362.

Hennessey, B. A. (2000). Self-Determination Theory and the Social Psychology of Creativity. Psychological Inquiry, $11,293-298$.

House, R. J. (1977). A 1976 Theory of Charismatic Leadership. In J. G. Hunt \&L. L. Larson (Eds.), Leadership: The Cutting Edge (pp. 189-207). Carbondale: Southern Illinois: University Press.

House, R. J., \& Shamir, B. (1993).Toward the Integration of Transformational, Charismatic, and Visionary Theories. In M. M. Chemers \& R. Ayman (Eds.), Leadership theory and research: Perspectives and directions. San Diego: Academic Press.

Hunt, J. G. (1991). Leadership: A new synthesis. Newbury Park, CA: Sage.

Judge, T. A., \& Piccolo, R. F. (2004). Transformational and Transactional Leadership: A meta-analytic test of their relative validity. Journal of Applied Psychology, 89, 755-768.

Kanungo, R. N., \& Mendonca, M. (1996). Ethical Dimensions of Leadership. Sage: Thousand Oaks, CA.

Kark, R., Shamir, B., \& Chen, G. (2003). Two Faces of Transformational Leadership: Empowerment and Dependency. Journal of Applied Psychology, 88(2), 246-255. 
Kirkman, B. L., Chen, G. L., Farh, J. L., Chen, Z. X., \& Lowe, K. B. (2009). Individual Power Distance Orientation and Follower Reactions to Transformational Leaders: A Cross-Level, Cross-Cultural Examination. Academy of Management Journal, 52, 744-764.

Lowe, K. B., \& Gardner, W. L. (2000). Ten years of The Leadership Quarterly: Contributions and Challenges for the Future. The Leadership Quarterly, 11, 459-514.

Menon, S. T, \& Borg, I. (1995). Facets of Subjective Empowerment. In Hox, J., \& Swanborn, P. (Eds.), Facet Analysis and Design (pp. 129-140). Zeist Press: Zeist, the Netherlands.

Psyszczynski, R., Greenberg, J., \& Solomon, S. (2000). Toward a Dialectical Analysis of Growth and Defensive Motives. Psychological Inquiry, 11, 301-305.

Ryan, R. M., \&Deci, E. L. (2000). Intrinsic and Extrinsic Motivations: Classic Definitions and New Directions.Contemporary Educational Psychology, 25, 54-67.

Shamir, B., House, R. J., \& Arthur, M. B. (1993). The motivational effects of charismatic leadership: A self-concept based theory. Organization Science, 4, 577-594.

Sheldon, K. M., \& Filak, V. (2008). Manipulating Autonomy, Competence, and Relatedness Support in a Game-Learning Context: New evidence that all three needs matter. British Journal of Social Psychology, 47, 267-283.

Spreitzer, G M. (1995). Individual Empowerment in the Workplace: Dimensions, Measurement, Validation. Academy of Management Journal, 38(5), 1442-1465.

Thomas, K. W., \& Velthouse, B. A. (1990). Cognitive Elements of Empowerment: an 'Interpretive' Model of Intrinsic Task Motivation. Academy of Management Review, 15, 666-681.

Vallerand, R. J., \& Reid, G. (1984). On the Causal Effects of Perceived Competence on Intrinsic Motivation: A Test of Cognitive Evaluation Theory. Journal of Sport Psychology, 6, 94-102.

Wang, H., Law, K. S., Hackett, R. D., Wang, D., \& Chen, Z. X. (2005). Leader-Member Exchange as a Mediator of the Relationship between Transformational Leadership and Followers' Performance and Organizational Citizenship Behavior. Academy of Management Journal, 48(3), 420-432.

Yukl, G. A. (1999). An Evaluation of Conceptual Weaknesses in Transformational and Charismatic Leadership Theories. The Leadership Quarterly, 10, 285-305.

Yukl, G. A. (2010). Leadership in Organizations (7th ed.). Englewood Cliffs, NJ: Prentice Hall. 